\title{
Retrofitting of RC Beams with Externally Bonded Simcon Laminates
}

\author{
R. Balamuralikrishnan* and C. Antony Jeyasehar
}

Department of Civil and Structural Engineering, Annamalai University, Annamalainagar - 608 002, Tamilnadu, India

\begin{abstract}
This paper presents the results of experimental and analytical studies concerning the flexural strengthening of $\mathrm{RC}$ beams using externally bonded Slurry Infiltrated Mat CONcrete (SIMCON) laminates. A total of four reinforced concrete beams were cast and tested in the laboratory over an effective span of $3000 \mathrm{~mm}$. Three beams were strengthened with bonded SIMCON laminate at the bottom under virgin condition and tested until failure; the remaining one beam was used as control specimen. Static responses of all the beams were evaluated in terms of strength, stiffness, ductility ratio, energy absorption capacity factor, compositeness between laminate and concrete, and the associated failure modes. The theoretical moment-curvature relationship for the test specimen and the load-displacement response of the strengthened beams and control beam were predicted by using FEA software ANSYS. Comparison was made between the numerical (ANSYS) with the experimental and theoretical results. The results show that the strengthened beams exhibit increased flexural strength, enhanced flexural stiffness, and composite action until failure.
\end{abstract}

Key Words: Composite beams, Fiber reinforced concrete, SIMCON, Flexural retrofit, Metal fibers.

\section{INTRODUCTION}

The cost of civil infrastructure constitutes a major portion of the national wealth. The rapid deterioration of reinforced concrete structures has thus created an urgent need for the development of novel, long-lasting and cost-effective methods for repair, retrofit and new construction. As the number of civil infrastructure systems increases worldwide, the number of deteriorated buildings and structures also increases. Complete replacement is likely to be an increasing financial burden and might certainly be a waste of natural resources if upgrading or strengthening is a viable alternative [1].

A promising new way of resolving this problem is to selectively use advanced composites such as HighPerformance Fiber Reinforced Cementitious Composites (HPFRCCs). With such materials novel repair, retrofit, and new construction approaches can be developed and that would lead to substantially higher strengths, seismic resistance, ductility, corrosion resistance and durability while also being faster and more cost-effective to construct than conventional methods [2]. In the present days life extension of structures through strengthening is becoming an essential activity. A host of strengthening systems has to be devised and adopted over the years. The choice of the strengthening system depends on the specific performance requirements. Plate bonding technique has gained widespread acceptance as a potential solution. Reinforcing concrete with steel greatly increases its usefulness as building materials. Although rebar and wire mesh provide the bulk of this reinforcement, steel fiber has gained an increasing share in the market. One promising new development uses steel fiber

*Address correspondence to this author at the Department of Civil and Structural Engineering, Annamalai University, Annamalainagar - 608002 , Tamilnadu, India; Tel: 91- 4144 - 239732:

E-mail:bmk_gaya@rediffmail.com mats (Fig. 1) to reinforce the concrete matrix. The new approach called SIMCON produces concrete components with extremely high flexural strength [3]. Since SIMCON is manufactured using pre-made continuous fiber mats, delivered in large rolls, fiber placement is substantially simplified.

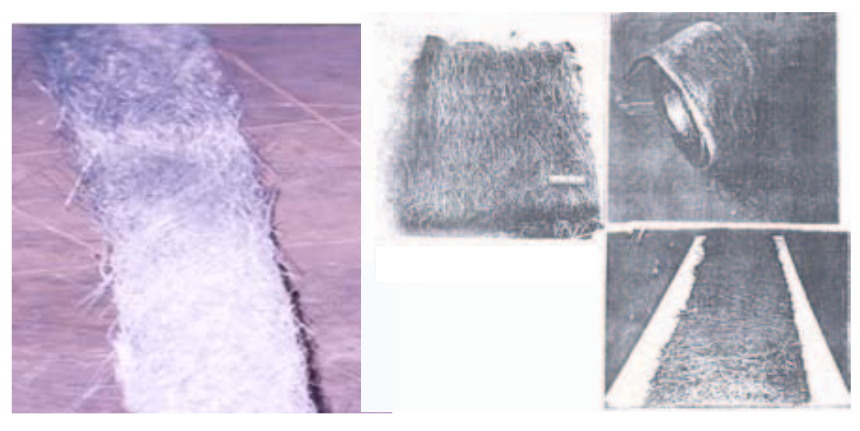

Fig. (1). Steel fiber mat.

Earlier, development SIFCON (Slurry Infiltrated Fiberous Concrete) was used in the field for retrofit and new construction. However, high placement cost and lack of fiber uniformity associated with manual distribution of discontinuous fibers have prevented its widespread field use [4]. All the above limitations can be overcome using SIMCON, which exhibits the improved features similar to SIFCON at a much lower fiber volume fraction. Since it is manufactured using pre-made continuous fiber mats, delivered in large rolls, fiber placement is substantially simplified [5].

SIMCON can also be considered a preplaced fiber concrete, the only difference being that the fiber is placed in a mat rather than discrete fibers. The fiber volume percent for manganese carbon steel mats ranged from 1.2 to 3.6 percent, while the stainless steel mats were placed to a density of 5.7 percent [6]. These fiber volumes can be increased somewhat by changing the fiber geometry. Fiber mat thickness ranges 
from $12 \mathrm{~mm}$ to $50 \mathrm{~mm}$. The result of manufacturing process is a filter-like fiber mat in which 60-70 percent of fibers are aligned in a longitudinal direction while the remaining 30-40 percent of fibers are oriented at an angle of up to 50 degrees to the longitudinal direction. The width of roles are in between 300 and $350 \mathrm{~mm}$ with weights up to $2.224 \mathrm{kN}$ for fibers made of steel with lengths of $300 \mathrm{~mm}$ or $350 \mathrm{~mm}$, with a density of $7842 \mathrm{~kg} / \mathrm{m}^{3}$ [7].

SIMCON laminates have shown great promise to upgrade structural systems. The present study has been taken up for evaluating the effects of strengthening Reinforced Concrete (RC) beams with externally bonded SIMCON laminates. An emphasis has been given to the strength and deformation properties of SIMCON laminated RC beams. The theoretical moment-curvature relationship for the test specimen and the load-displacement response of the strengthened beams and control beam was predicted by using FEA software ANSYS. Comparison is made between the numerical (ANSYS) and the experimental results and suitable conclusions are drawn based on the results obtained from laboratory experiments and theoretical analysis.

\section{EXPERIMENTAL INVESTIGATION}

Preliminary experimental study was conducted to determine the optimum volume fraction and aspect ratio of fiber mat. Fourty-five laminates of size $125 \times 25 \times 500 \mathrm{~mm}$ were cast with different volume fraction $\left(\mathrm{V}_{\mathrm{f}}\right)$, say 4.0 percent, 4.5 percent, 5.0 percent, 5.5 percent, and 6.0 percent and different aspect ratio (1/d) say 300, 400, and cocktail of 300 and 400. Among these combination the test results is found that $\mathrm{V}_{\mathrm{f}}=5.5$ percent gives better performance with regard to ultimate load (U.L) and stiffness.

In this study uniform and mixed aspect ratio, say 300 , 400 , and cocktail of 300 and 400 were used, so that the length of the fiber is 150 and $200 \mathrm{~mm}$, respectively, in such a way that as per volume fraction 60 percent of fibers aligned in the longitudinal direction and the remaining 40 percent of fibers aligned in the inclined direction not exceeding 50 degrees with the horizontal. Every mat has four or five layers of fibers as per $\mathrm{V}_{\mathrm{f}}$ and the individual fibers are bonded with low viscosity epoxy resin that should not affect the voids between the individual fibers for achieving perfect cement grout. The final form of the fiber mat is just like filter mat. After spraying the resin the mat was held in position by compression machine under $50 \mathrm{kN}$ at 30 minutes and then allowed for 24 hours air curing. Then the fiber mats were kept in the mould and were grouted; the cement slurry was mixed in a mortar mixer with super plasticizer for improving workability with reduced water cement ratio and to have adequate fluidity in order to facilitate construction of specimens. Hence great care has been taken in choosing the constituent materials based on different trial mix. Mixing ratio of the cement slurry is given below:

Sand /cement

Water/cement ratio

Super plasticizers / Cement

Conplast 430 is used as super plasticizer. The purposes for which the admixture is used are as follows: water reduction, which increases strength and reduces permeability; improvement in impermeability; and air entrainment, which increases resistance to freezing and thawing. It is used for binding individual fiber and it posses very high mechanical and adhesive strength properties most desirable for civil engineering applications. Hand compaction and gravity feeding were used to produce thorough penetration of slurry into the preplaced steel fibers. Curing of SIMCON laminates was accomplished by covering with plastic sheets for 24 hours, followed by water submersion for 28-days after the curing period. The completed SIMCON laminates of size $125 \times 250 \times 2950 \mathrm{~mm}$ has one volume fraction and three aspect ratios, viz: $\mathrm{V}_{\mathrm{f}}=5.5$ percent and aspect ratio $300, \mathrm{~V}_{\mathrm{f}}=5.5$ percent and aspect ratio 400 and $\mathrm{V}_{\mathrm{f}}=5.5$ percent and cocktail aspect ratio of 300 and 400 (Fig. 2). Total of 4 beams, $125 \times 250 \times 3200 \mathrm{~mm}$ in size, were cast and tested in the laboratory over an effective span of $3000 \mathrm{~mm}$. Of the above four beams, one beam was used as control specimens (CB1), and three beams (RB1, RB2 and RB3) were strengthened with bonded SIMCON laminates $(125 \times 250 \times 2950 \mathrm{~mm})$ at the bottom under virgin condition and tested until failure. The details of test beams are presented in Table 1.

The beams are under reinforced section [8], reinforced with 2-12 \# at bottom, 2-10 \# at top using 6mm dia stirrups @ $150 \mathrm{~mm} \mathrm{c} / \mathrm{c}$ (Fig. 3). M 20 concrete and Fe 415 grade steel are used.

The soffit of the beams were sand blasted to remove the surface laitance and then blown free of dust using compressed air. After surface preparation, the adhesive components were mixed thoroughly and applied to the surface using a trowel. The SIMCON laminates already cast were placed over the beam and held in position by dead weights. The strengthened beams were tested after the interval of 14days. The coin tap was conducted to identify areas of

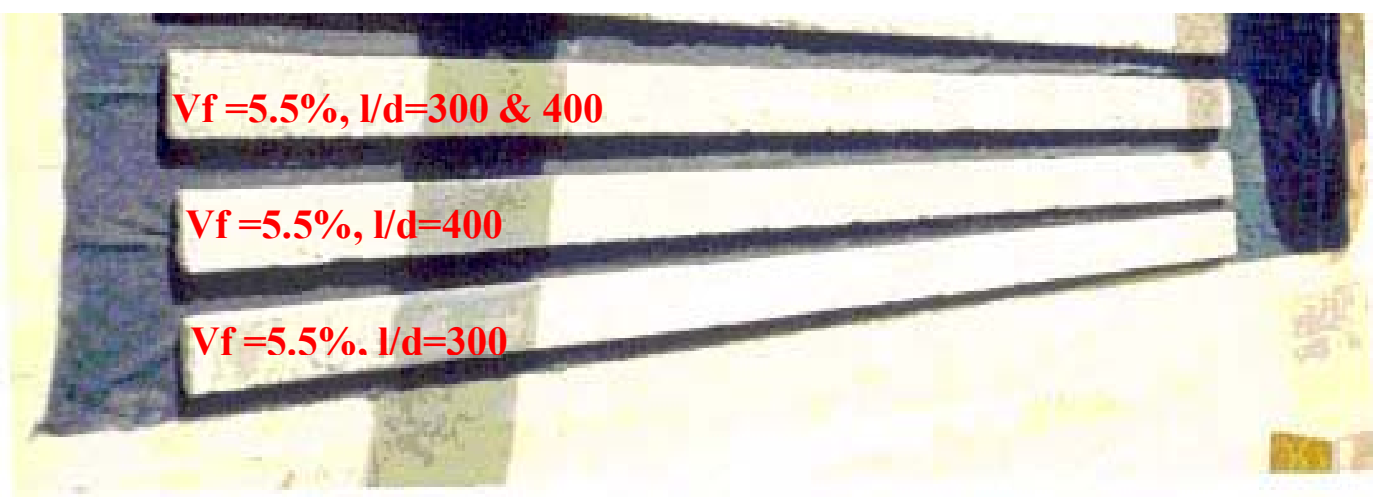

Fig. (2). SIMCON Laminates. 
Table 1. Beam Designation

\begin{tabular}{|c|c|c|c|c|c|c|c|c|}
\hline \multirow{2}{*}{ Sl. No } & \multirow{2}{*}{ Beam Number } & \multirow{2}{*}{ Beam Type } & \multicolumn{2}{|c|}{ Laminate Details } & \multicolumn{4}{|c|}{ Laminate Properties } \\
\hline & & & $\begin{array}{c}\text { Volume } \\
\text { Fraction }\left(V_{f}\right)\end{array}$ & $\begin{array}{c}\text { Aspect } \\
\text { Ratio (1/d) }\end{array}$ & $\begin{array}{c}\text { Compressive } \\
\text { Strength } \mathbf{N} / \mathbf{m m}^{2}\end{array}$ & $\begin{array}{c}\text { Tensile } \\
\text { Strength } \mathbf{N} / \mathbf{m m}^{2}\end{array}$ & $\begin{array}{c}\text { Modulus of } \\
\text { Elasticity } \mathbf{N} / \mathbf{m m}^{2}\end{array}$ & $\begin{array}{l}\text { Density } \\
\mathrm{kg} / \mathrm{m}^{3}\end{array}$ \\
\hline 1. & $\mathrm{CB} 1$ & Control Beam & - & - & - & - & - & - \\
\hline 2. & RB1 & $\begin{array}{c}\text { SIMCON } \\
\text { laminated beam }\end{array}$ & $\begin{array}{c}5.5 \\
\text { percent }\end{array}$ & 300 & 88 & 17 & $2.2 \times 10^{4}$ & 7695.97 \\
\hline 3. & RB2 & $\begin{array}{c}\text { SIMCON } \\
\text { laminated beam }\end{array}$ & $\begin{array}{c}5.5 \\
\text { percent }\end{array}$ & 400 & 85 & 15 & $2.1 \times 10^{4}$ & 7675.65 \\
\hline 4. & RB3 & $\begin{array}{c}\text { SIMCON } \\
\text { laminated beam }\end{array}$ & $\begin{array}{c}5.5 \\
\text { percent }\end{array}$ & $\begin{array}{l}300 \text { and } \\
400\end{array}$ & 80 & 14 & $2.0 \times 10^{4}$ & 7670.52 \\
\hline
\end{tabular}

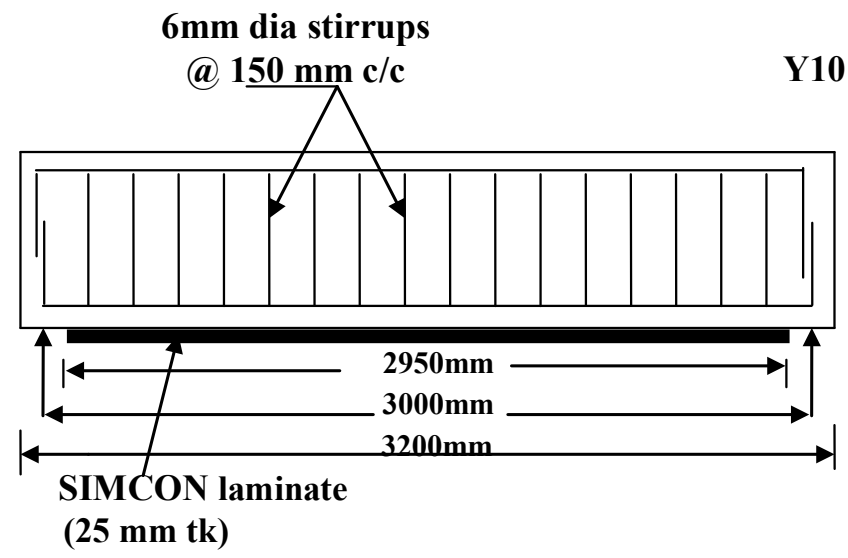

Longitudinal Section
10 -2 Nos.

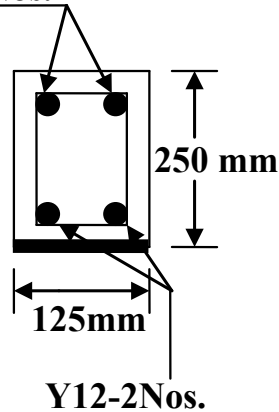

$\underline{\text { Cross Section }}$

Fig. (3). Longitudinal and Cross Section of Strengthened.

debond, if any. Beams were tested in four point bending as shown in Fig. (4).

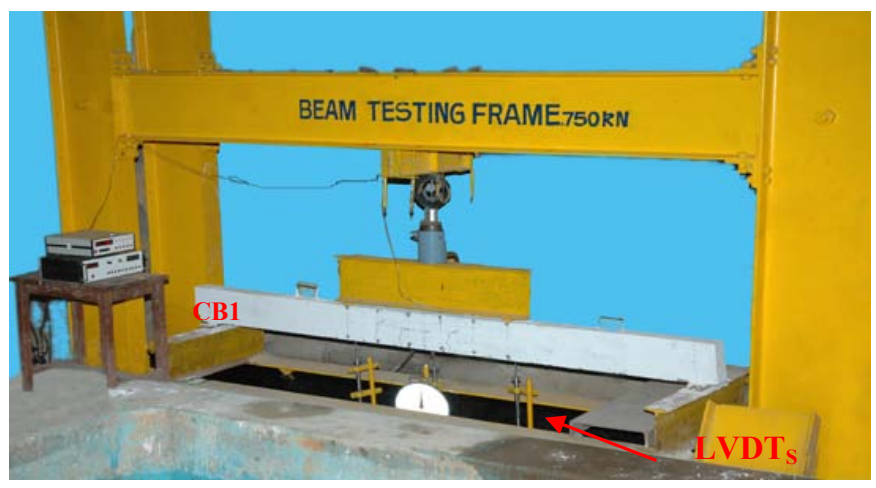

Fig. (4). Test Set Up for Static Loading.

Load, displacement and strains have been recorded. For each specimen electrical strain gauges were fixed at mid span of tension reinforcement and at the mid span of bottom surface of bonded SIMCON laminates in the longitudinal direction. Concrete having mean cube compressive strength of $27.54 \mathrm{MPa}$ was used. Ordinary Portland cement, natural river sand and the crushed granite of maximum size $20 \mathrm{~mm}$ were used. High yield strength deformed (HYSD) bars of 12 and $10 \mathrm{~mm}$ diameter with mean strength of $512 \mathrm{~N} / \mathrm{mm}^{2}$ were used as longitudinal reinforcement and $6 \mathrm{~mm}$ diameter mild steel bars were used for internal links. The elastic modulus of the concrete is $2.4 \times 10^{4} \mathrm{~N} / \mathrm{mm}^{2}$. Three numbers of SIMCON laminates of $25 \mathrm{~mm}$ thick were used for externally strengthening the RC beams. A two-part epoxy adhesive (corocretin $1 \mathrm{HS}$ - BV comp A1 as a base material and corocretin $1 \mathrm{HS}-\mathrm{BV}$ comp B1 as a hardener with filler for corocretin A1 - 100/200 and filler for corocretin B1- 300 mesh) with paste like consistency was used to bond laminates to the beam soffits. The adhesive had an ultimate tensile strength of $34.80 \mathrm{~N} / \mathrm{mm}^{2}$ and elastic modulus of $1500 \mathrm{~N} / \mathrm{mm}^{2}$. For all the test beams, the parameters of interest were ultimate load, mid-span deflection, 1/3 span (both left and right) deflections, composite action, and failure modes. All the test beams were over designed for shear to avoid the undesirable brittle failure. The SIMCON laminate thickness of $25 \mathrm{~mm}$ and bond line thickness $2.0 \mathrm{~mm}$ were kept constant for all the test specimens.

\section{TESTING AND MEASUREMENTS}

All the beams were tested under four point bending, the load of which was monotonically increased. The vertical mid-span and $1 / 3^{\text {rd }}$ span deflections were measured using mechanical dial gauges of $0.01 \mathrm{~mm}$ accuracy and electrical strain gauges were used for finding the steel strain and composite strain. The crack development and propagation were monitored and marked during the progress of the test. The crack widths were measured using a crack detection microscope of $0.02 \mathrm{~mm}$ precision. 


\section{SUMMARY OF TEST RESULTS}

The test results on the strength and deformation properties of the control specimen and strengthened beams are reported in Table $\mathbf{2}$ and $\mathbf{3}$.

A quantitative measure of ductility has to be with reference to a load-deflection response. Then, the ratio of the ultimate deformation to the deformation at the beginning of the horizontal path (or, at first 'yield') can give a measure of ductility. However, each choice of deformation (strain, rotation, curvature, or deflection) may give a different value for the ductility measure [9].

Energy absorption capacity can be measured under the area of stress-strain curve (load-deflection cure). The first crack loads were obtained by visual examination only. The experimental ultimate loads were obtained corresponding to the load beyond which the beam would not sustain additional deformation at the same load intensity. Based on the experimental results, it can be observed that significant increase in strength can be realised at all the load levels by externally bonding SIMCON laminates. This increase may be attributed to the increase in tensile cracking strength of concrete due to confinement. Further it is to be noted that increase in load carrying capacity is possible only when other modes of failure do not interfere. All the strengthened beams were also carefully examined prior to and after testing. It was found that failure did not occur at the laminate-concrete interface. This confirms that the composite action continued throughout the load spectrum. The load-mid span deflection graphs were drawn for control and strengthened beams as shown in Fig. (5). From the graph it is seen that beam RBlexhibits increased deflection and flexural strength.

Table 2. Summary of Test Results

\begin{tabular}{|c|c|c|c|c|c|c|c|c|c|}
\hline \multirow{2}{*}{ Beam Code } & \multicolumn{2}{|c|}{ First Crack Stage } & \multicolumn{2}{|c|}{ Service Stage } & \multicolumn{2}{|c|}{ Yield Stage } & \multicolumn{2}{|c|}{ Ultimate Stage } & \multirow{2}{*}{$\begin{array}{c}\text { Average } \\
\text { Crack Width } \\
\text { at Service } \\
\text { Load }(\mathbf{m m})\end{array}$} \\
\hline & $\begin{array}{l}\text { Load } \\
(\mathrm{kN})\end{array}$ & $\begin{array}{c}\text { Central } \\
\text { Deflection }(\mathbf{m m})\end{array}$ & $\begin{array}{c}\text { Load } \\
(\mathrm{kN})\end{array}$ & $\begin{array}{c}\text { Central } \\
\text { Deflection }(\mathbf{m m})\end{array}$ & $\begin{array}{c}\text { Load } \\
(\mathbf{k N})\end{array}$ & $\begin{array}{c}\text { Central } \\
\text { Deflection }(\mathbf{m m})\end{array}$ & $\begin{array}{c}\text { Load } \\
(\mathbf{k N})\end{array}$ & $\begin{array}{c}\text { Central } \\
\text { Deflection }(\mathbf{m m})\end{array}$ & \\
\hline $\mathrm{CB} 1$ & 15 & 3.38 & 27.5 & 14.08 & 34.37 & 17.60 & 41.25 & 21.13 & 0.11 \\
\hline $\mathrm{RB} 1$ & 45.0 & 6.88 & 55.0 & 18.67 & 69.75 & 23.33 & 82.50 & 28.00 & 0.08 \\
\hline $\mathrm{RB} 2$ & 40.0 & 5.14 & 52.0 & 16.67 & 67.0 & 20.80 & 78.0 & 25.00 & 0.11 \\
\hline RB3 & 37.5 & 4.68 & 46.0 & 15.47 & 58.5 & 19.38 & 69.0 & 23.21 & 0.12 \\
\hline
\end{tabular}

Table 3.

\begin{tabular}{|c|c|c|c|c|}
\hline Beam Code & Ductility Factor & Energy Capacity Factor & Post Cracking-Pre yielding Stiffness $\left(\mathbf{k N m} \mathbf{m}^{2}\right) \mathbf{M}$ & $\mathbf{o d e}$ of Failure \\
\hline \hline CB1 & 1 & 1 & 860 & Flexure \\
\hline RB1 & 1.7219 & 1.644 & 2785 & Flexure \\
\hline RB2 & 1.3415 & 1.242 & 2545 & Flexure \\
\hline RB3 & 1.384 & 1.366 & 2335 & Flexure \\
\hline
\end{tabular}

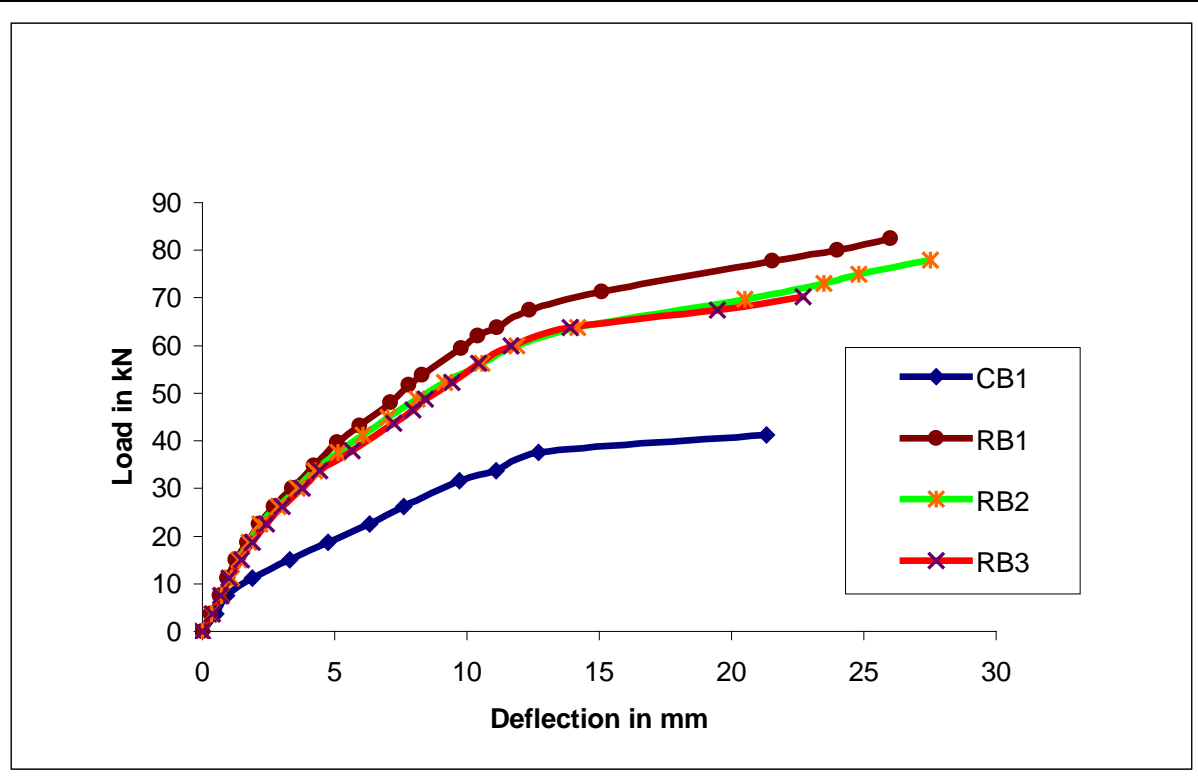

Fig. (5). Load-Deflection Curves. 
During the test, the crack patterns in the beams were noted and the crack patterns were closely analysed. The crack patterns of the beams are shown in Fig. (6) and also the crack width of control beam (CB1) and strengthened beams (RB1, RB2 and RB3) are reported in Table $\mathbf{2}$ and $\mathbf{3}$.

\section{NUM ERICAL (ANS YS) RE SULTS O F L OAD- DEFLECTION BEHAVIOUR}

FEA software ANSYS is adopted for predicting the loaddisplacement response of the control and strengthened beams numerically. The mesh model defined 375 nodes and 47 elements. The programme offers solid 65 for beam element (Fig. 7), link 8 for steel element (Fig. 8) and solid 45 for laminate element [10]. The generated model for beam RB1 is shown in Fig. (9). A typical deflected shape of strengthened beam RB1 is shown in Fig. (10). A comparison of loaddeflection and strain variation arising out of numerical analysis with that of experimental investigation has been presented in section 6 .

\section{THEORETICAL LO AD-DEFLECTION BEHAVIOUR (SECTION ANALYSIS)}

The theoretical multilinear moment curvature $(\mathrm{M}-\phi)$ relationships were derived for the control beam following the procedure given in Park and Paulay1975 [11]. The three important stages or points identified in the M- $\phi$ curve are the cracking stage, yielding stage, and ultimate stage. In this study one more stage which corresponds to the start of non-

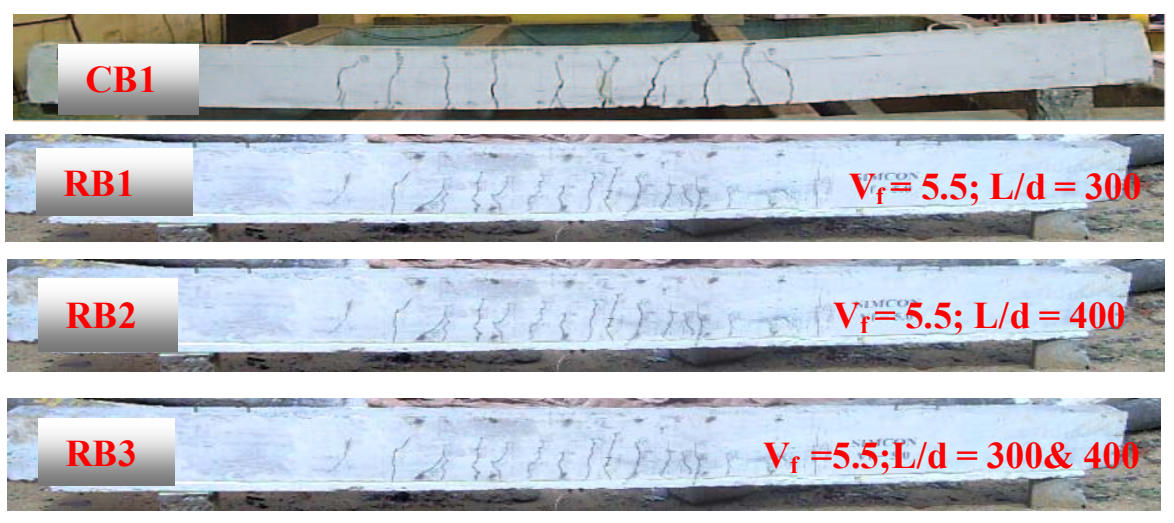

Fig. (6). Crack Pattern of Tested Beams (CB1, RB1, RB2 \& RB3).

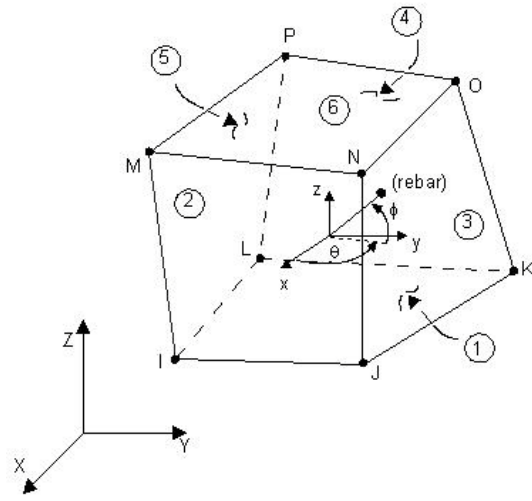

Fig. (7). Solid65 and Solid45 Geometry.
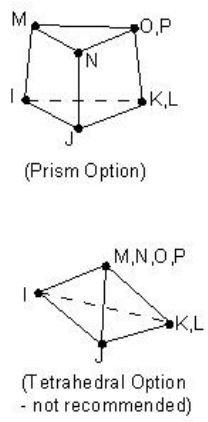

(Tetrahedral Option
- not recommended)

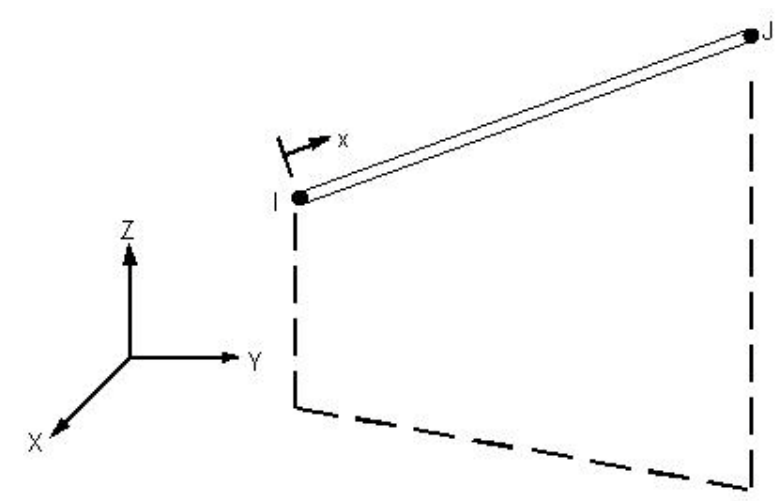

Fig. (8). Link8 Geometry.

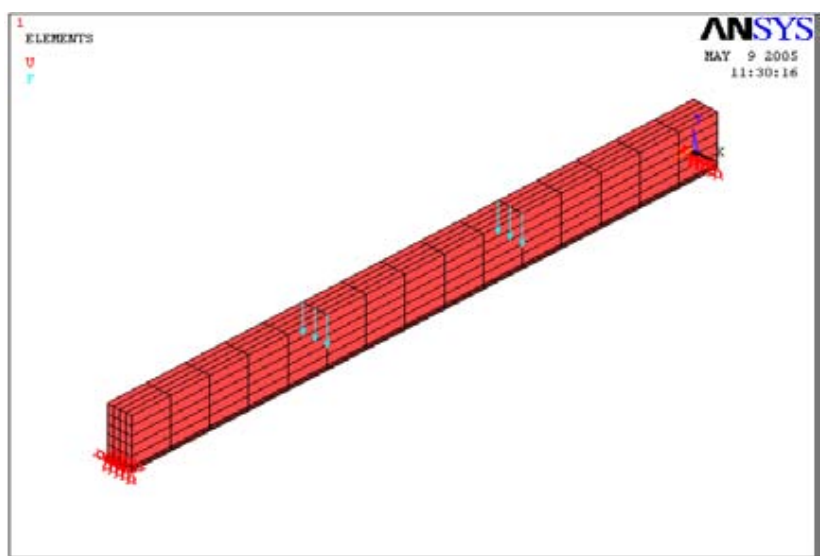

Fig. (9). Element Discretization, Loading Pattern and Boundary Conditions in FEA. 
linearity in stress strain curve of steel is proposed [12] and thus making it a multilinear curve. From the multi linear $\mathrm{M}$ $\phi$ relationship multilinear load-deflection curve was derived by adopting a curvature distribution similar to that of a bending moment variation and conjugate beam method of analysis. The same procedure was adopted for uncracked beams bonded with SIMCON laminates of different aspect ratio. The experimental, numerical (ANSYS), and theoretical load- deflection curves are compared for both control beam (CB1) and strengthened beams RB1 in Figs. (11) and (12). It can be seen that the predicted deflections are in close agreement with the experimental results. Comparisons of ultimate loads for experimental, numerical (ANSYS), and theoretical (Section Analysis) results are shown in Table 4. The details presented in Tables $\mathbf{2}$ and $\mathbf{3}$ show that the beam RB1 is performing well in all respects.

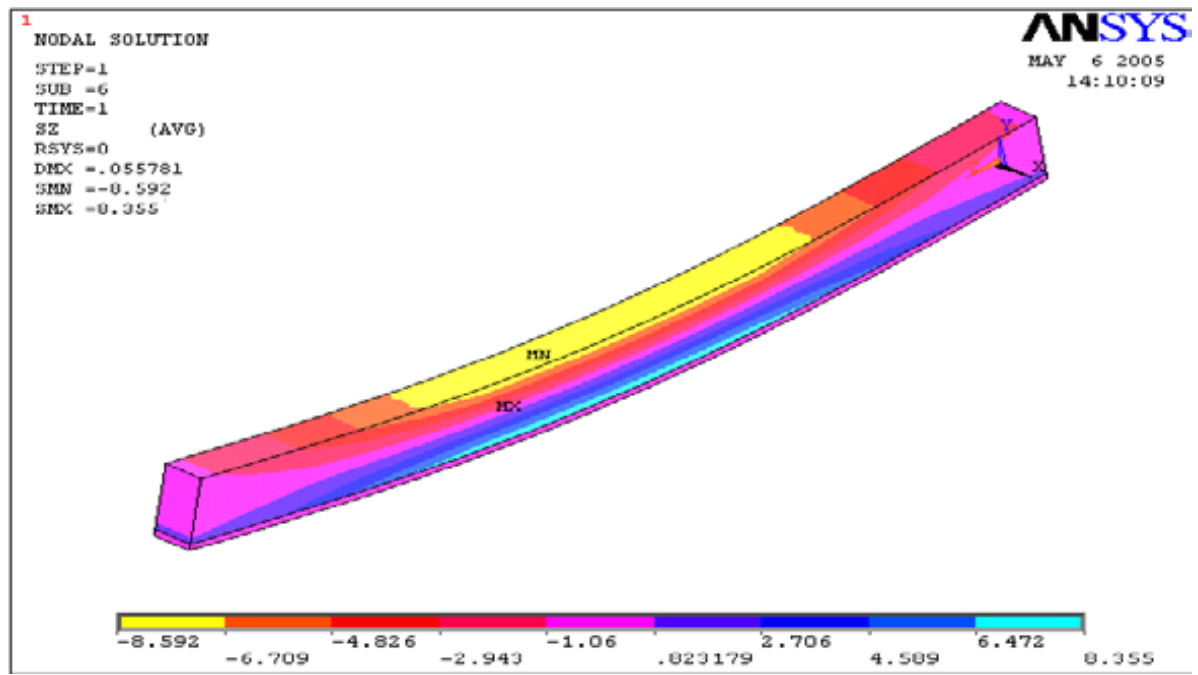

Fig. (10). Deflected Shape of Strengthened Beam RB1 (ANSYS).

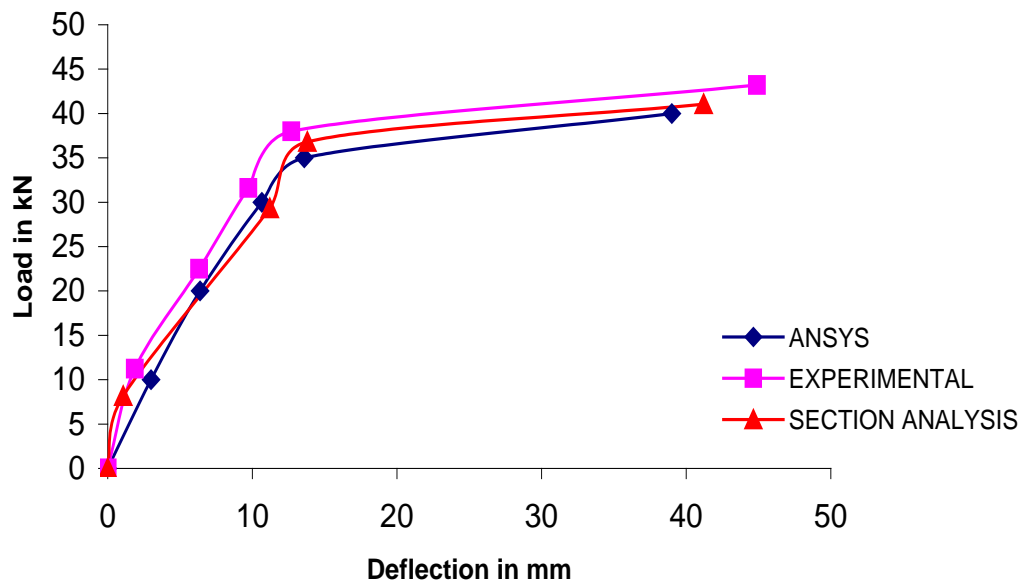

Fig. (11). Load - Deflection Curve for Control Beam CB1.

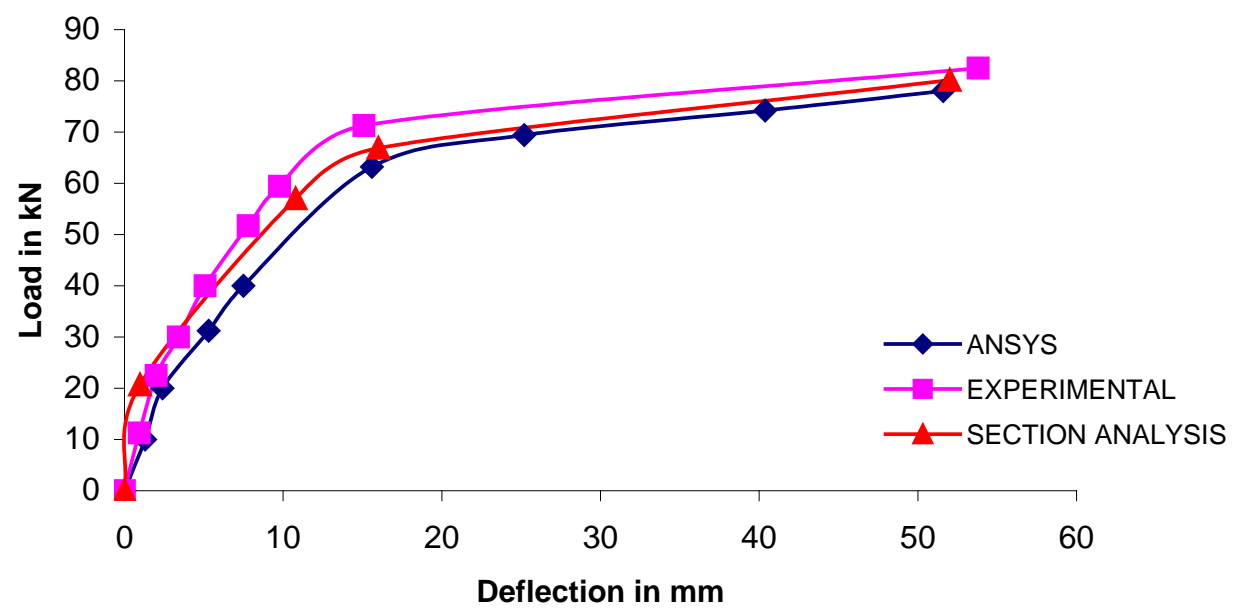

Fig. (12). Load - Deflection Curve for strengthened Beam RB1. 
Table 4. Comparisons of Ultimate Loads

\begin{tabular}{|c|c|c|c|c|c|c|c|}
\hline \multirow{2}{*}{ SI. No } & \multirow{2}{*}{ Detail of Beam } & \multicolumn{3}{|c|}{ Ultimate Loads in kN } & \multicolumn{3}{c|}{ Percentage Increase in Flexural Capacity } \\
\cline { 3 - 8 } & & Experimental N & $\begin{array}{c}\text { umerical } \\
\text { (ANSYS) }\end{array}$ & $\begin{array}{c}\text { Theoretical } \\
\text { (Section Analysis) }\end{array}$ & Experimental N & $\begin{array}{c}\text { umerical } \\
\text { (ANSYS) }\end{array}$ & $\begin{array}{c}\text { Theoretical } \\
\text { (Section Analysis) }\end{array}$ \\
\hline \hline 1. & CB1 & 41.25 & 40.00 & 41.06 & - & - & 95 \\
\hline 2. & RB1 & 82.50 & 78.00 & 80.14 & 100 & 88.75 & 85.18 \\
\hline 3. & RB2 & 78.00 & 75.50 & 76.40 & 89.09 & 45.45 & 45.94 \\
\hline 4. & RB3 & 60.00 & 58.00 & 59.10 & & 45 \\
\hline
\end{tabular}

\section{CONCLUSIONS}

Based on the results obtained from experiments, analytical and theoretical analyses, the following conclusions are drawn:

1. SIMCON laminates properly bonded to the tension face of RC beams can enhance the flexural strength substantially. The strengthened beams exhibit an increase in flexural strength of 45.45 percent for laminates having volume fraction 5.5 percent and aspect ratio 300 and 400, 89.09 percent for volume fraction 5.5 and aspect ratio 400 , and 100 percent for volume fraction 5.5 percent and aspect ratio 300 .

2. At any given load level, the deflections are reduced significantly thereby increasing the stiffness for the strengthened beams. At ultimate load level of the control specimens, the strengthened beams exhibit a decrease of deflection up to 87 percent.

3. All the beams strengthened with SIMCON laminates with optimum volume fraction 5.5 percent and aspect ratio 300, 400, and 400 and 300 experience flexural failures. None of the beams exhibit premature brittle failure.

4. A flexible epoxy system will ensure that the bond line does not break before failure and participate fully in the structural resistance of the strengthened beams.

5. Among the three different volume fraction and aspect ratio of bonded SIMCON laminates, the strengthened beam RB1 of volume fraction 5.5 percent and aspect ratio 300 exhibit 100 percent increase in flexural strength when compared to the control specimen and has close agreement with the experimental, theoretical calculations (section analysis) and numerical (ANSYS) results.
6. The ultimate loads from the finite element analysis are lower than the ultimate loads from the experimental results by 3.10 percent to 5.80 percent. The ultimate loads from the theoretical calculations (section analysis) are lower than the ultimate loads from the experimental results by 0.50 percent to 2.90 percent.

\section{REFERENCES}

[1] L. C. Hollaway and M. B. Leeming, Strengthening of reinforced concrete $s$ tructures $u$ sing e xternally-bonded FRP $c$ omposites in structural and civil engineering. England: CRC Press, 1999.

[2] Z. Bayasi and J. Zeng, "Flexural behaviour of slurry infiltrated mat concrete (SIMCON)”, ACI Struct. J., vcl. 9(4), pp. 194-199, November 1997.

[3] E.L. Hackmen, M.B. Farrel and O.O. Dunham, "Simcon infiltrated mat concrete (SIMCON)", Concr. In t., vol. 14(12), pp.53-56, November 1992

[4] N. Krstulovic-Opara, E. Dogan, C.-M.Uang and A. R. Haghayeghi, "Flexural behaviour of composite RC-slurry infiltrated mat concrete (SIMCON) members", ACI Mater. J., vol. 94(5), pp. 502-512, September-October 1997.

[5] N. Krstulovic-Opara and S. Malak, "Tensile behaviour of slurry infiltrated mat concrete (SIMCON)", ACIM ater. J., vol 94(1), pp.39-46, January-February 1997.

[6] N. Krstulovic-Opara and M.J. Al-Shanng, "Compressive behaviour of slurry iinfiltrated mat concrete (SIMCON)", ACI Mater. J., vol. 96(3), pp. 367-377, May-June 1999a.

[7] N. Krstulovic-Opara and M. J. Al-Shanng, "Slurry infiltrated mat concrete (SIMCON) based shear retrofit of reinforced concrete members", ACI Struct. J., vol.96 (1), pp.105-114, January-February $1999 b$.

[8] IS 456, Code of practice for reinforced concrete design, New Delhi: Bureau of Indian Standards, 2000.

[9] U. Pillai and D. Menon, Reinforced concrete design, New Delhi: McGraw- Hill Publishing Co Ltd., 2002.

[10] User Manual, ANSYS 7, USA: Ansys. Inc. Houston, 2002.

[11] R. Park, and T. Paulay, Reinforced concrete structures, New York: John Wiley and Sons, 1975.

[12] C. A. Jeyasehar, "Damage assessment of reinforced concrete beams using non- destructive testing methods", PhD thesis, IIT Madras, Chennai, January 1999. 